\title{
Changes in perceptions of border security influence desired levels of immigration
}

\author{
Ryan C. Briggs* $\quad$ Omer Solodoch ${ }^{\dagger}$
}

\begin{abstract}
Security concerns about immigration are on the rise. Many countries respond by fortifying their borders. Yet little is known about the influence of border security measures on perceived threat from immigration. Borders might facilitate group identities and spread fear of outsiders. In contrast, they might enhance citizens' sense of security and control over immigration. We test these claims using survey experiments run on a nationally representative sample of over 1,000 Americans. The findings show that allocating more government resources to border security increases desired levels of immigration. This effect is likely driven by a sense of control over immigration, induced by border security measures even when the number or characteristics of immigrants remain unchanged. Our findings suggest that border controls, which are widely considered as symbols of closure and isolation, can promote openness to immigration.
\end{abstract}

${ }^{*}$ University of Guelph, Guelph Institute of Development Studies and Department of Political Science. rbriggs@uoguelph.ca

${ }^{\dagger}$ Browne Center for International Politics, University of Pennsylvania and Department of International Relations, Hebrew University of Jerusalem. solodoch@sas.upenn.edu 
Unprecedented numbers of refugees in recent years were met with a growing sense of threat surrounding international borders (Simmons and Shaffer, 2019). Increasingly, destination countries respond to this perceived threat by hardening their borders (Simmons and Kenwick, 2021). They deploy law enforcement personnel along their borders, and build walls, fences, and barriers to further secure them. From the United States to the European Union, from Hungary to France, Germany and Sweden, border controls are implemented not only by right-wing populist or anti-immigrant forces, but rather by a diverse set of political actors across the globe (Brown, 2010). However, little empirical work examines the implications of increasing border security on the politics of immigration. Do border controls mitigate or magnify perceived threats from, and public opposition to, immigration?

One line of thinking generally assumes that borders facilitate group identities and define group membership. Thus, when nation states build more along their borders, they strengthen national bonds of belonging, spread fear of "the other," and perpetuate the social exclusion of immigrants. The idiom "build bridges, not walls" draws upon this notion and suggests that the social construction of borders should intensify this sense of a "us against them." Instead of building walls that divide natives and immigrants, both literally and figuratively, the slogan demands governments to build symbolic bridges that connect people together. According to this perspective, when governments implement border controls, natives' hostility to immigrants should follow. This view was also shared by Pope Francis who said, in response to rising concerns about the global refugee crisis, that "...Europe is in difficulty, it's true... We must find solutions. We must encourage dialogue between differ- 
ent nations... Walls are never solutions. But bridges are, always, always."1

Yet despite its prevalence, the belief that borders spread fear and perpetuate conflict is not unchallenged. Some have pointed out that when borders are perceived to be weakened by immigration, native citizens may experience a sense of external threat, which can prompt an identity reaction, where exclusionary identities emerge in other forms to "reclaim the group boundaries previously defined by geographic borders" (Simmons and Goemans, 2021, p. 35). The political insight of Former Australian Prime Minister John Howard (2015) is in line with this prediction:

"My long experience in Australian politics has been that whenever a government is seen to have immigration flows under control, public support for immigration increases. When the reverse occurs, hostility to immigration rises."

Consistent with Howard's observation from Australia, historical changes in border security in the United States were positively associated with Americans' desired levels of immigration. As Figure 1 shows, border patrol agents and spending on border security skyrocketed over the past three decades. Meanwhile, the share of Americans supporting for increasing immigration levels grew by 460 percent (or 22 percentage points). Other factors could account for the variation in both outcomes, of course. Whether this association reflects a spurious correlation or stems to some extent from the direct, causal

\footnotetext{
${ }^{1}$ AA Politics, September 28, 2015. "Europe urged to build bridges, not walls for refugees." Available at: www.aa.com. This view was also shared by many other politicians, world leaders, and international organizations. See, for example: (1) UN SecretaryGeneral, Ban Ki-moon (2) London Mayor, Sadiq Khan; and (3) Presidential Candidate, Hillary Clinton.
} 
effect of border security measures on desired levels of immigration remains an open question.

Figure 1: Border security and support for immigration, United States

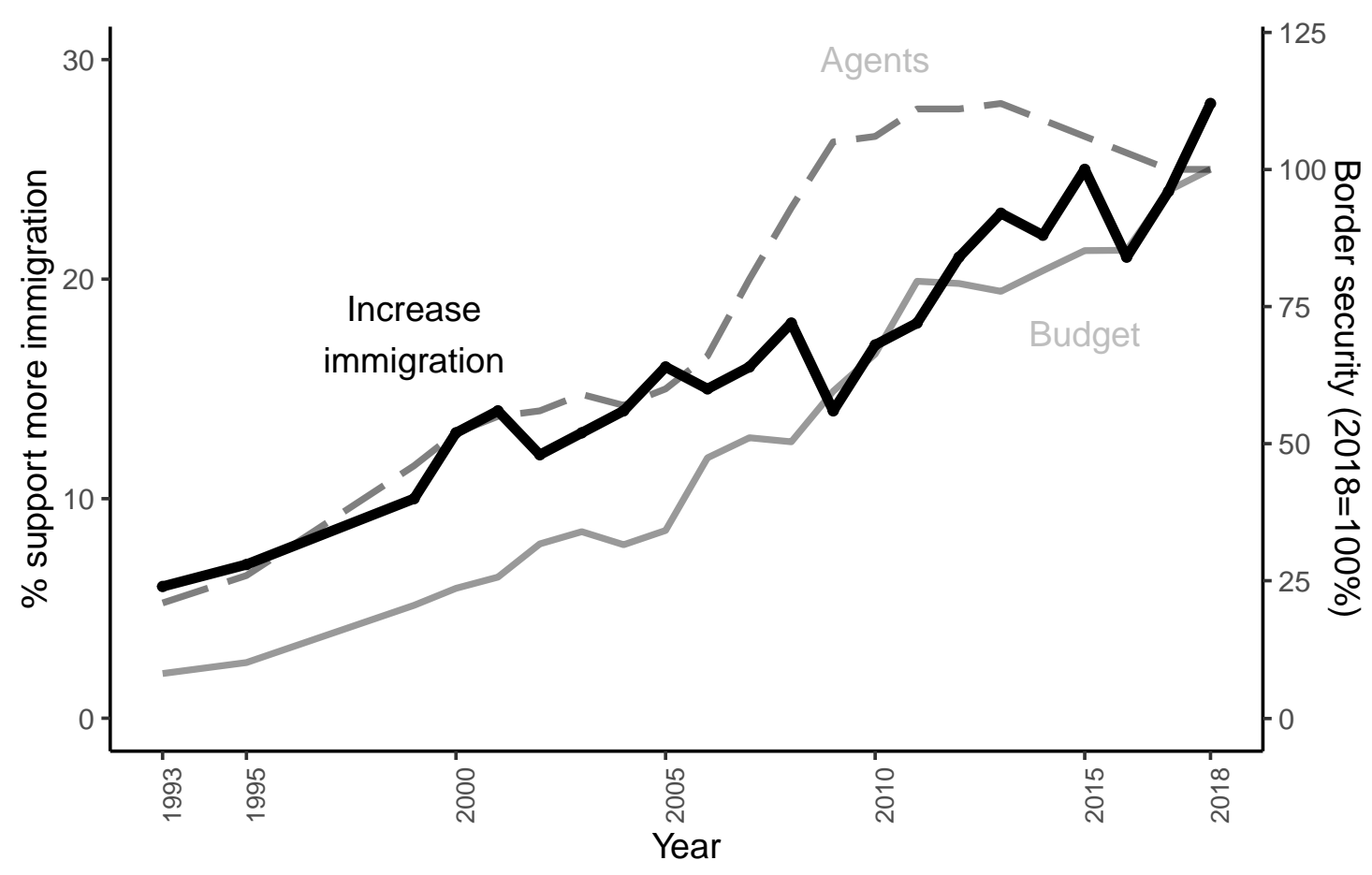

Notes: Public attitudes toward immigration (black line) are from Gallup, based on the question: "Thinking now about immigrants - that is, people who come from other countries to live here in the United States, in your view, should immigration be kept at its present level, increased or decreased?" Data on personnel on the southern border (dashed gray line) are from the Department of Homeland Security, U.S. Customs and Border Protection. Data on border security budget (solid gray line) are from the American Immigration Council, available at: https://www.americanimmigrationcouncil.org/research/thecost-of-immigration-enforcement-and-border-security. Both indicators of border security are set to show growth over time, where the final data point, 2018, equals 100\% (agents: 16,608; budget: $\$ 4.458$ billion).

This article provides a theoretical underpinning and empirical analysis to assess the control hypothesis that people condition their level of support for immigration on control of immigration flows. One major way to control immigration flows is to closely police borders. We propose that when people 
view the permeability of national borders as a security issue, they will respond to increases in border security by feeling more in control. This sense of security and control then enables people to be more willing to welcome outgroup members to their country. The inverse should also hold, with declines in perceived control over borders leading people to feel more insecure and thus turn towards ingroups and become less welcoming of immigrants.

We test the control hypothesis using two pre-registered, nationally representative survey experiments run on over 1,000 Americans. Both experiments suggest that respondents are willing to have higher levels of immigration when spending on border security increases and that they want lower levels of immigration when spending on border security declines. Notably, though, we also find a ceiling effect: the marginal effect of increasing border security spending declines, indicating that relatively small increases in spending achieve a level of support for immigration similar to substantial increases in spending.

A key problem faced by research on the impact of immigration policy is that policy change almost always have expected implications on the number and characteristics of immigrants. If a host country implements stronger border controls, the number of unauthorized immigrants trying to cross the border might decrease. Natives might also expect that the economic or cultural composition of the immigrant population would change as borders become more secure. To explore whether the effect of border security stems from a regained sense of control over immigration, or rather from perceived changes in the number or characteristics of immigrants, we utilize a conjoint experiment that manipulates both the policy at the border and the size and 
composition of the immigrant population. The findings show that when the border is more closely policed, natives' perceived control over immigration significantly increases, even though the immigrants' number and characteristics are held constant.

The article's findings contribute to our understanding of the implications of borders on domestic and international politics. One widely held view in the literature is that borders facilitate divisions between insiders and outsiders, "us" and "them" (Longo, 2017; Mendez and Naples, 2014). Another view is that border security measures are usually counterproductive: i.e., they rarely meet their goals, be it curtailing immigration or countering terrorist attacks, and they have very little material benefits but significant ramifications to the nations that build them (Longo, Canetti, and Hite-Rubin, 2014; Carter and Poast, 2019; Schon and Leblang, 2021; Linebarger and Braithwaite, 2020) ${ }^{2}$ In contrast, our analysis reveals that measures of border security might mitigate public backlash and facilitate immigrant inclusion. This indicates that people might react to the symbolic meaning of the border more than to its material outcomes. But while some people see borders as symbols of division and isolation, others - those who more often perceive immigration as a potential security threat- see borders as symbols of security, sovereignty, and control.

Our findings also add to extant research on the effects of immigration policies (Hainmueller, Hangartner, and Pietrantuono, 2015; Hainmueller, Hangartner, and Pietrantuono, 2017; Solodoch, 2021; Marbach, Hainmueller, and Hangartner, 2018; Fouka, 2019; Abdelgadir and Fouka, 2020). Specifi-

\footnotetext{
${ }^{2}$ But see Avdan and Gelpi (2016).
} 
cally, this study suggests that those trying to increase immigration and advance immigrant inclusion should be aware of the potential counterproductive effect of promoting the idea of "open borders." Opening the country's gates and increasing levels of immigration is more likely to win public support when the national borders are perceived as secure and under control. Taken together with previous work, the cumulative evidence indicates that different domains of policy require different approaches to achieve what governments usually define as favorable outcomes. Whereas policy liberalization often enhances immigrant integration (e.g., Marbach, Hainmueller, and Hangartner, 2018; Abdelgadir and Fouka, 2020), the same approach on border security, our findings show, can spark a political backlash and hinder the social inclusion of immigrants.

\section{Theoretical Background}

A long-standing intuition in extant literature is that interstate borders strengthen national identities and group categorization. Its philosophical roots date back to David Hume who observed that the national character of peoples is shaped by the boundaries of their governments' authority. $\left.\right|^{3}$ According to this view, in addition to defining the territory of nation states and the limits of their sovereignty, borders also delineate political communities. They determine group membership and define who belongs to the national community (Migdal, 2004; Longo, 2017). These bonds of belonging and internal inclusion

\footnotetext{
3 "The same national character commonly follows the authority of government to a precise boundary; and upon crossing a river or passing a mountain, one finds a new set of manners, with a new government" (Hume, 2018, p. 167).
} 
of a bounded citizenry, facilitate, by definition, external exclusion - the exclusion of the non-citizens who are on the other side of the border (Brubaker, 2009; Joppke, 2008).

The theory of social construction is deeply embedded in this top-down line of thinking: government policies, such as border security measures, identify and construct groups as deserving (citizens) and undeserving (immigrants). These constructions, which amplify intergroup differences and become permanent lines of political cleavages, gain legitimacy. The result of this process of social construction is an "other," a group of marginalized people widely viewed as undeserving outsiders (Schneider and Ingram, 2005).

Indeed, scholars often posit that state borders not only mirror the transformations in the definitions of citizenship and national identity (Donnan and Wilson, 2021), but also influence group identity, strengthen national loyalties, and deepen divisions between insiders and outsiders (Simmons and Goemans, 2021; Sambanis and Shayo, 2013; Miles and Rochefort, 1991; Newman, 2006). Beyond group categorization, border controls can also associate immigration with security issues, such as violent crime or terrorism. According to social construction theory, more secured and well-defined borders should therefore frame immigrants as an external threat and heighten public opposition to immigration.

Yet the logic of social construction tends to amplify the divisive aspects of borders and dismiss their protective aspects - the possibility that some citizens see borders as providing protection from preexisting external threats. Namely, if social identities are already strongly held by people, then nationality and ethnicity will remain key determinants of group categorization and 
exclusion after policy changes at the border. People will not only adhere to their key identity characteristics when borders are removed or opened and external, physical boundaries erode, they will even further entrench themselves in their old inner boundaries of group identity (Newman, 2006; Simmons and Goemans, 2021). Such an identity backlash was observed following the fall of the iron curtain that led to the reopening of the border between Georgia and Turkey (Pelkmans, 2011), as well as after the fall of the Berlin wall in Germany (Andrews, 2003). In the words of Walzer (2008, p. 39): "To tear down the walls of the state is not to create a world without walls, but rather to create a thousand petty fortresses."

In addition, immigration controls are understood as a national security issue in many countries (Bigo, 2002; Huysmans, 2006; Ibrahim, 2005, Lahav and Courtemanche, 2012). When cross-border flows of people are perceived as a threat, actions that reduce the policing of cross-border flows will be perceived as increasing threat.

The perception of porous borders and the sense of losing control over immigration seem to tap into deep-seated fears of a foreigner takeover and the loss of national sovereignty. In the face of threat, people turn more toward their familiar in-group (Stenner, 2005; Gelfand et al., 2011). Consistent with this conjecture, Angela Merkel's "open-door" policy was followed by the rise of the far right AfD party, while in the United Kingdom, "taking back control" over immigration policy after the Brexit referendum reduced anti-immigrant attitudes (Schwartz et al., 2020) and initiated the collapse of UKIP.

The control hypothesis we propose in this paper is that when people 
feel that their national borders are uncontrolled or less secure they become less welcoming of immigration. We also expect the inverse relationship to hold. If people think that their national borders are more secure then we expect that they will feel safer and thus be supportive of higher levels of immigration. Notably, these relationships should be stronger in countries where immigration is a salient national issue and where flows across borders are understood as threatening.

In addition to perceptions of control, changes in border security measures might influence desired levels of immigration through a "perceived selection" channel. In particular, increases in border security might make citizens expect for a decrease either in the total number of incoming migrants or in the number of people from near-border countries of origins, leading to a change in the composition of the immigrant population. Since the number and characteristics of migrants shape public opinion on immigration (Hainmueller and Hopkins, 2015), the effect of border security measures might also stem from changes in perceived selection $4^{4}$ We next turn to our research design.

\section{Experiment 1}

We first test the control hypothesis using a survey experiment run on a Qualtrics-conducted national survey of 1,015 respondents in the United States.$^{5}$

\footnotetext{
${ }^{4}$ However, correcting for misperceptions about the number and characteristics of migrants has a limited effect on attitudes toward immigration and no impact on policy views (Hopkins, Sides, and Citrin, 2018, Grigorieff, Roth, and Ubfal, 2017).

${ }^{5}$ Qualtrics interviewed 1,374 respondents between May 16, 2019 to May 24, 2019. As noted in our pre-registration documents, people who completed the survey in less than $30 \%$ of the median response time, people who said they were under 18 , or people who did not consent to the study were dropped. This left 1,015 respondents. Respondents were
} 
The analysis was pre-registered before the survey was run ${ }^{6}$

The goal of the first experiment is to directly test if one's desired level of immigration changes in response to changes in the expected security of national borders. Following the theory above, we expect increases in border security to raise desired levels of immigration and decreases to lower desired levels of immigration. We change perceptions of border security by asking respondents to consider if the federal government increased or decreased spending on border security by between 1 and $25 \%$. We use changes in spending on border security for three reasons. First, these changes are easily understood by respondents. Second, resource changes are plausible. Third, working with resource changes allow for smooth and symmetric treatment values, which would not be possible with qualitative descriptions of increases or decreases in border security[]

The experiment runs as follow: we first inform respondents that the historical level of immigration to the US over the past decade has been about 1 million immigrants per year. We then ask respondents to "move the slider to show approximately how many immigrants you think the US should accept per year." The slider starts centered on 1 million and ranges from 0 to 2 million. This creates a control value that is intentionally anchored around the current rate.

selected via quota sampling, balancing on gender, region of the US, and age categories. Using the 2018 CPS and following our pre-registration plan, we then calculated weights via raking to balance on gender, state of residence, age categories, and education categories. See Appendix B for further discussion of the survey weights.

${ }^{6}$ EGAP [REDACTED]. Appendix C notes all deviations from the pre-registration plan.

${ }^{7}$ In the third experiment, instead of changes in border security spending we assess the effect of tight border controls, a border fence, or a border wall, compared to having no border controls. Results remain substantively identical. 
We later ask respondents to do the same activity but the prompt is modified so that they are told to "Move the slider below to show approximately how many immigrants you think the US should accept if the federal government were to [increase/decrease] spending on border security by $x$ percent," where increase or decrease is randomized and where $x$ is a randomly selected number between 1 to 25 (inclusive). Finally, respondents are given the same prompt with another random value of $x$ and with the opposite increase/decrease value that they saw before. In this setup, each person creates first a control immigration value and then two treated immigration values, one from a randomly sized increase in border spending and one with a randomly sized decrease in border spending. We are ultimately interested in deviations from the control value under the treatment conditions. One advantage of this approach is that we are capturing within-respondent information, which should have lower noise than a cross-respondent design 8

Following our pre-registration plan, we drop observations with control dependent variable values that are in the most extreme $1 \%$ of either end of the distribution. This was done to reduce the noise created by outlying people who unthinkingly dragged the slider to the hard limits of the range. We then calculate a change score, which is the difference between the treatment values and the control dependent variable, and we drop change score values that

\footnotetext{
${ }^{8}$ One drawback to this design is that it could lead to demand effects. Recent research has suggested that demand effects may be very small if they exist at all (Mummolo and Peterson, 2019) and has recommended pre/post designs to increase precision without introducing bias (Clifford, Sheagley, and Pisont, 2021). While this is comforting, we can also check the results of this experiment against those of the second and third experiments, where it will be much more difficult for the respondent to work out which of the profiles would best match our theory (which of course was not revealed to the respondent). The results are substantively similar.
} 
are in the most extreme $1 \%$ of either end of the change score distribution. Again the goal is to reduce noise introduced by respondents who may not have taken the exercise seriously.

In the main text, we graphically present the relationship between the change score (desired immigration level under treatment - desired immigration level under control) and the randomly assigned changes to spending on border security. In appendix A, we present tabular results of a regression where we regress the desired level of immigration under the treatment condition on the randomly assigned change in spending on border security and the desired level of immigration under the control condition. In either case each respondent contributes two data points, and in the regressions we cluster standard errors by respondent.

\section{Results}

Figures $2 \mathrm{a}$ and $2 \mathrm{~b}$ graphically present the results from the first analysis, where the y-axis shows the change in the desired number of immigrants from the control condition to the treatment condition and the $\mathrm{x}$-axis is the magnitude of the change in border security spending in the treatment condition. Figure $2 \mathrm{a}$ shows means (in blue) for each value of the treatment variable. The red line is a loess fit. In Figure 2b, we show the average desired change in the number of immigrants in response to changes of up to 10 percent and between 11 and 25 percent in border security spending.9

Respondents want higher levels of immigration to the United States when

\footnotetext{
${ }^{9}$ For clarity Figure $2 \mathrm{a}$ shows a crop of the full figure containing approximately $71 \%$ of all observations. Figure A-1 in Appendix A shows the same figure but zoomed out to show all the data points.
} 
Figure 2: Effect of border spending change on desired level of immigration

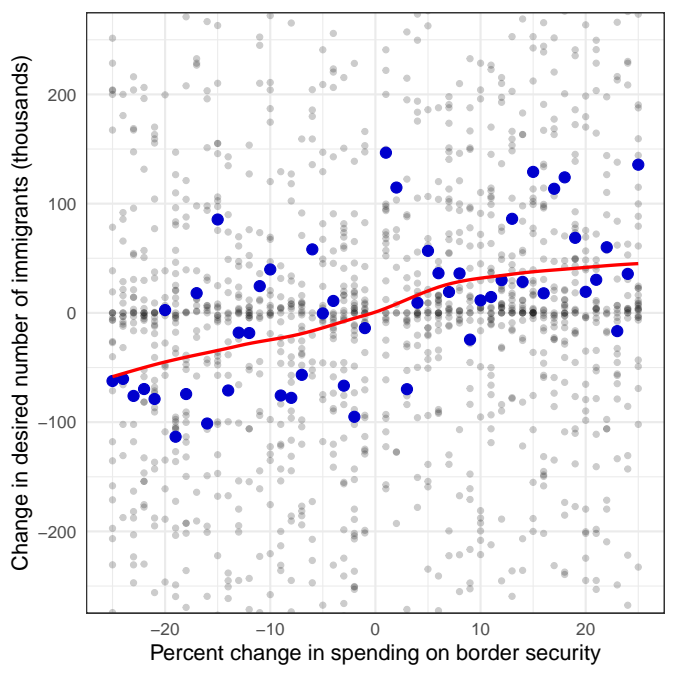

(a) Full range

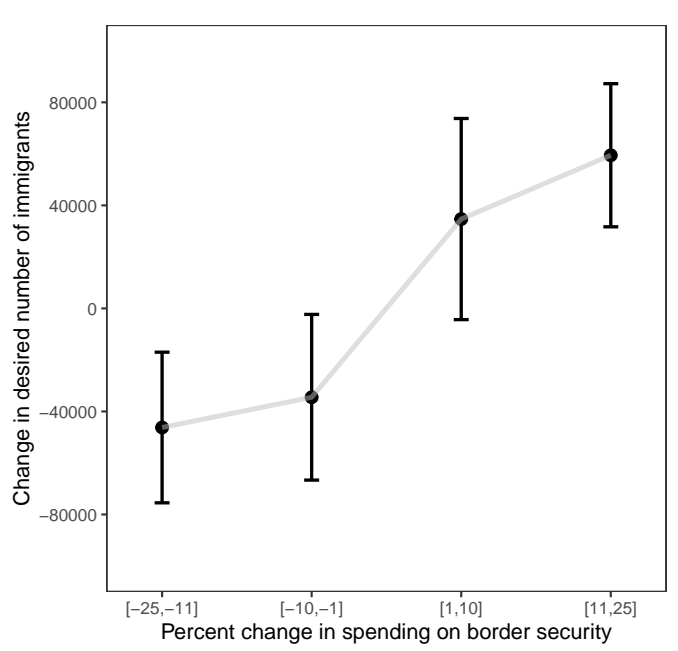

(b) Binned

Notes: Both panels show the effect of change in spending on border security (horizontal axis) on change in desired number of immigrants (vertical axis, in thousands only in panel (a)). Panel (a) shows means for each value of the treatment variable (in blue). The red line is a loess fit. Panel (b) shows means for four grouped ranges of values, indicating more clearly a decreasing marginal effect on both sides of the continuum.

spending on border security increases, and they want lower levels of immigration when spending on border security decreases. These results are consistent with the control hypothesis. When fitting a linear model to the same data, the effect of border spending on immigration changes is significant at $p<$ 0.001 .10

As Figure 2b shows, respondents prefer approximately 35,000 more (less)

\footnotetext{
${ }^{10}$ Comfortingly, there is no desired change in the number of immigrants when the change in border spending is zero (see Figure 2a). Tabular results are in Appendix A. As per our pre-registration plan, the tabular results come from a linear model that regresses the desired immigration level under the treatment condition on the change in border spending and the desired immigration level under the control condition. Standard errors are clustered on respondents.
} 
immigrants in response to an increase (decrease) of between 1 and 10 percent in border security spending. Yet compared to relatively modest changes in spending, the marginal effect of more substantial changes is small, indicating that excessive modifications in border security measures have a similar impact on desired levels of immigration. The significant and sizable treatment effect is therefore driven more by a change in desired immigration levels around the shift of from negative to positive spending on border security.

\section{Experiment 2}

The first experiment offers a direct test of the claim that resources devoted to border security cause changes in desired levels of immigration. The second experiment was designed to test an observable implication of the control hypothesis and was embedded in the same Qualtrics national survey. This is an example of a paired design, where a "second experiment is conducted to determine whether the results of the first are robust before knowing the results of the first" (Sniderman, 2018, p. 270). If it is true that one's desired level of immigration is conditioned by perceptions of border security, then one should be more likely to desire policy changes that increase immigration when they are paired with an increase in border spending, and the inverse should also be true. We test to see if this pattern exists with a conjoint experiment that we run after the first experiment. Respondents see two modifications to current policy, each with two attributes: resources devoted to border control and the official immigration rate. Each attribute of each policy has a randomly assigned value that proposes an increase or decrease 
Figure 3: An example of the conjoint experiment.

\begin{tabular}{|c|c|c|}
\hline Modification A & & Modification B \\
\hline $\begin{array}{l}10 \% \text { less spent on border } \\
\text { security }\end{array}$ & $\begin{array}{l}\text { Resources devoted to } \\
\text { border control }\end{array}$ & $\begin{array}{l}15 \% \text { more spent on border } \\
\text { security }\end{array}$ \\
\hline $\begin{array}{c}0 \% \text { decrease from prese } \\
\text { of immigration }\end{array}$ & fficial immigration rate & $\begin{array}{c}\text { \% decrease from prese } \\
\text { of immigration }\end{array}$ \\
\hline
\end{tabular}

Which modification to current immigration policy would you prefer? Modification A

Modification B

in border spending or the immigration rate ${ }^{11}$ Respondents are then asked to select the modification that they prefer. An example screen is shown in Figure 3. Respondents do this 7 times, producing a total of 14 observations per respondent. 12

We are interested in testing for an interaction between the two independent variables, and we test for this in two ways. First, we split the sample by whether or not border spending increased or decreased in each profile and then we run a simple bivariate regression of the binary dependent variable in the level of immigration for both sub-samples. ${ }^{13}$ The key prediction here is that people will be more likely to select profiles with higher levels of immigration when border spending is increasing. Second, we simply run an OLS regression of the binary dependent variable on each of the two independent

\footnotetext{
${ }^{11}$ The values range from $-20 \%$ to $+20 \%$ in $5 \%$ increments. The middle value is "No change from present policy."

${ }^{12}$ One may worry about question fatigue when doing the same conjoint task 7 times, but existing evidence suggests that respondents exhibit similar behavior when completing up to 30 such tasks (Bansak et al., 2018).

${ }^{13}$ While this analysis uses the same variables as those listed in the pre-registration plan, it is a somewhat different setup. Appendix $\mathrm{C}$ reports the results of the pre-registered test and explains why we shifted to this analysis strategy after seeing the data.
} 
variables and their interaction, where each independent variable runs from 1 to 9 and is treated as continuous.

We present results for the full sample and then in the appendix also for the subgroups of people who claimed in experiment one to want: less immigration, more immigration, and those who prefer the current rate ${ }^{14}$ The results of the second experiment are consistent with the results of the first, which further substantiates our main conclusions.

\section{Results}

The first experiment directly tests how desired immigration levels respond to changes in spending on border security. The second experiment tests one implication of the theory, which is that people should be more willing to select policies that increase immigration if these policies are paired with increases to spending on border security.

Figure 4 shows that people are more likely to select profiles with higher rates of immigration when they are paired with increases in border security spending. When border security spending is reduced or unchanged, respondents are 10 percentage points more likely to opt for a substantial 20-percent reduction in immigration. In contrast, when border security spending is increased, respondents are not more supportive of curtailing immigration (compared to no change), and even tolerate a sizable increase of 10 percent in the

\footnotetext{
${ }^{14}$ Following our pre-registration plan, we made the subsamples by dividing respondents by their response to the control dependent variable slide question from the first analysis. Respondents who wanted fewer than 925,000 immigrants are classified as wanting to "allow fewer immigrations" while those who wanted an immigration level of more than 1,075,000 people per year were classified as wanting to "allow more immigrants." Those in between were said to "prefer current rate."
} 
level of immigration. Only the largest two values of immigration changes affect respondents when border security spending is increased, and even then, the 8-point effect is more than twice as large when border security spending is reduced or unchanged $(\mathrm{p}<0.05) 15$

Figure 4: How immigration levels and border spending interact to change the probability of profile selection

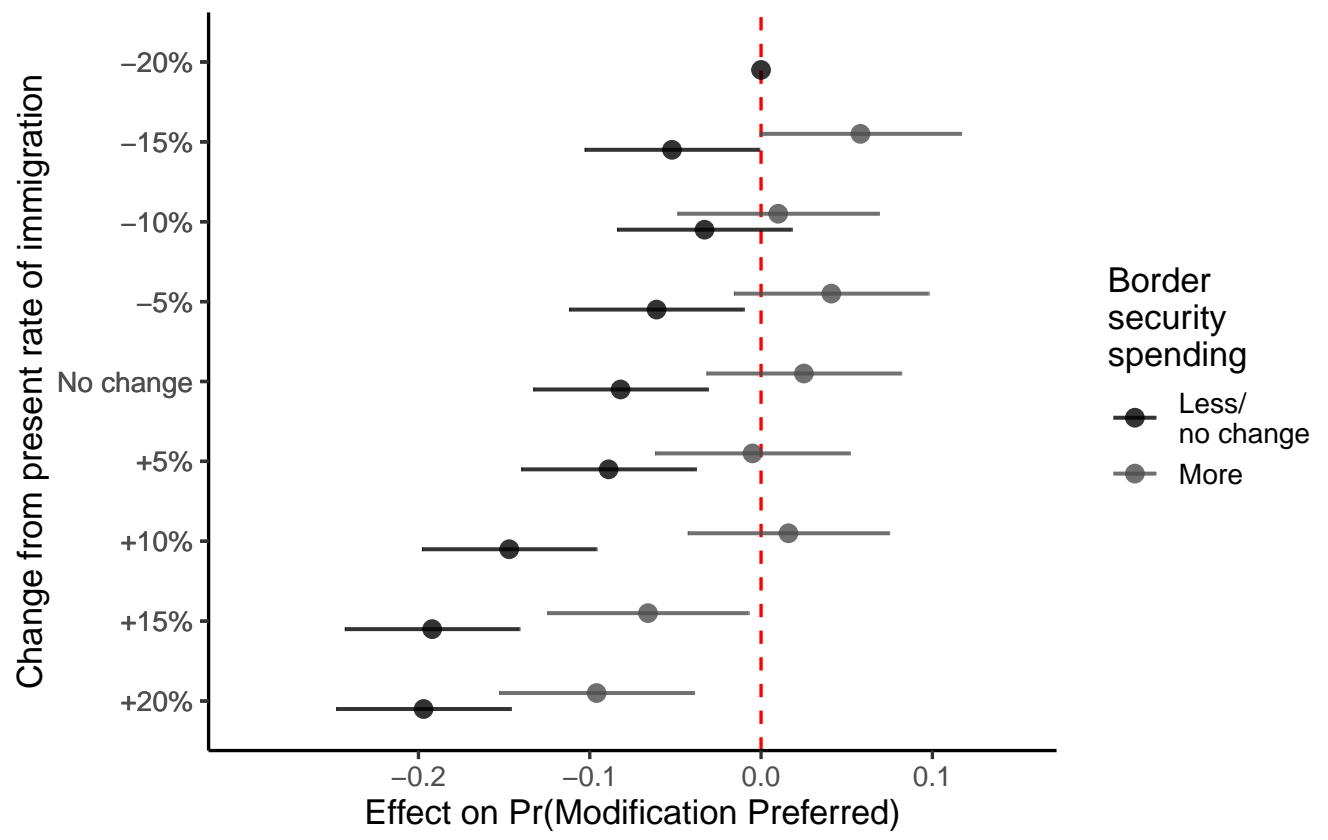

Notes: This figure shows estimates of the effects of the randomly assigned values of changes in the rate of immigration on the binary outcome variable that equals 1 if the modification is preferred by respondents. Estimates are based on two ordinary least squares models controlling for respondent fixed effects (since each respondent evaluates seven paired profiles): one model for modifications that include either less or no change in border security spending (black coefficients) and a second model for modifications in which border security spending is increased (gray coefficients). Bars represent $95 \%$ confidence intervals. The point without horizontal bars denote the attribute value that is the reference category.

\footnotetext{
${ }^{15}$ To formally test the interaction effect we run an OLS regression of the binary dependent variable on the immigration treatment that runs from 1 to 9 , the dummy for increased border security spending, and their interaction terms (see Appendix Table A-5 column 3). Seven out of eight interaction terms are statistically significant $(\mathrm{p}<0.05)$.
} 
Finally, in Table A-6, we divided our sample to three groups based on their pre-treatment immigration preferences: those who wanted less immigration, those who wanted more immigration, and those who favored the current level of immigration. For each gourp, we regressed the binary dependent variable marking profile selection on the change in border spending and the change in immigration and the interaction of the two. The effect of immigration levels is most significantly and consistently moderated by border security spending for the group who preferred a decrease in current levels of immigration. This suggests that border security measures increase support for immigration primarily by appeasing people closer to the anti-immigration side of the debate, rather than uniformly affect the electorate or further heightening support in the pro-immigration camp.

In sum, the analyses of the second experiment largely affirm the results of the first experiment. The average respondent was less likely to select a profile if it had a higher rate of immigration, but this effect was significantly weaker if the increase in immigration was paired with an increase in border spending. Like the results of the first experiment, this evidence is consistent with the control hypothesis.

\section{Experiment 3}

The third experiment was designed to test the causal mechanism underlying the control hypothesis - that border security affects public attitudes toward immigration by increasing people's sense of control over immigration. We do so by (1) neutralizing the selection channel - the number and character- 
istics of immigrants - through which border controls might also affect public attitudes; and (2) measuring respondents' perceptions of control over immigration directly.

The experiment presents survey respondents with randomly assigned scenarios of immigration. These scenarios are comprised of two key components. One component is a border security policy ${ }^{16}$ Border controls could be completely lacking, tight, or based on a border fence or a border wall. A second component randomly allocates immigrant characteristics, broadly defined. For example, the annual authorized flow of immigrants could be as low as 10,000 , or as high as $1,000,000$ visa admissions. The same levels of immigration flows apply for annual unauthorized entries. Holding the level of immigration constant ensures that the causal effect of policy does not stem from expected changes in immigration flows following the policy. Similarly, the experiment also manipulates the cultural background and the professional skill set of immigrants in each potential scenario. Therefore, border security effects on perceived control over immigration, if found significant, will not be driven by immigrant selection.

The paired conjoint experiment presents two scenarios at a time, side by side. Then, subjects are asked to rate each scenario, using two survey items: (1) "On a scale from 0 to 10 , where 0 indicates that the US has absolutely no control over immigration and 10 indicates that the US has complete control over immigration, how would you rate each scenario?", and (2) "On a scale from -5 to 5 , where -5 indicates that the impact of immigration on the US as a

\footnotetext{
${ }^{16}$ To reduce demand effects, the experiment manipulated five different policy types. All of these treatments are fully controlled for in the analysis, but we choose to present only border controls in the main text for the sake of clarity. The full version of this analysis is presented in figure A-2.
} 
whole is very negative and 5 indicates that it is very positive, how would you rate each scenario?" Thus, the experiment begins with collecting people's perceived control over immigration and only then proceeds to estimating whether policy also shapes people's evaluations of immigration as a negative or positive phenomenon.

We recruited survey respondents on Mechanical Turk (MTurk) in March 2020 ${ }^{17}$ Respondents were invited to take part in a survey on social policy in the United States. Each of the 166 respondents rated five pairs of profiles of potential immigration scenarios, which generated a sample size of 1,660 observations.

\section{Results}

Figure 5 shows the effect of the policy at the border on people's perceived control over immigration (left panel) and positive evaluations of immigration (right panel). Markers represent point estimates with 95\% confidence intervals. Reference categories are represented by the upper dots in each set of values with no confidence intervals. All coefficients are drawn from an OLS fixed-effects model, where the outcome variable is the 0-10 perceived control scale, and all of the treatments are the independent variables. The individual-level fixed effects control for all respondents' characteristics that remain fixed over the evaluation of the ten conjoint scenarios.

Results show that the marginal effect of having border security measures over no border controls increases perceived control over immigration by 1

\footnotetext{
${ }^{17}$ To collect American respondents, we restricted the location of MTurk workers allowed to answer the survey to the United States only and their "special characteristics" to be at least with a US high-school diploma.
} 
Figure 5: Border controls, immigration flows, and attitudes toward immigration

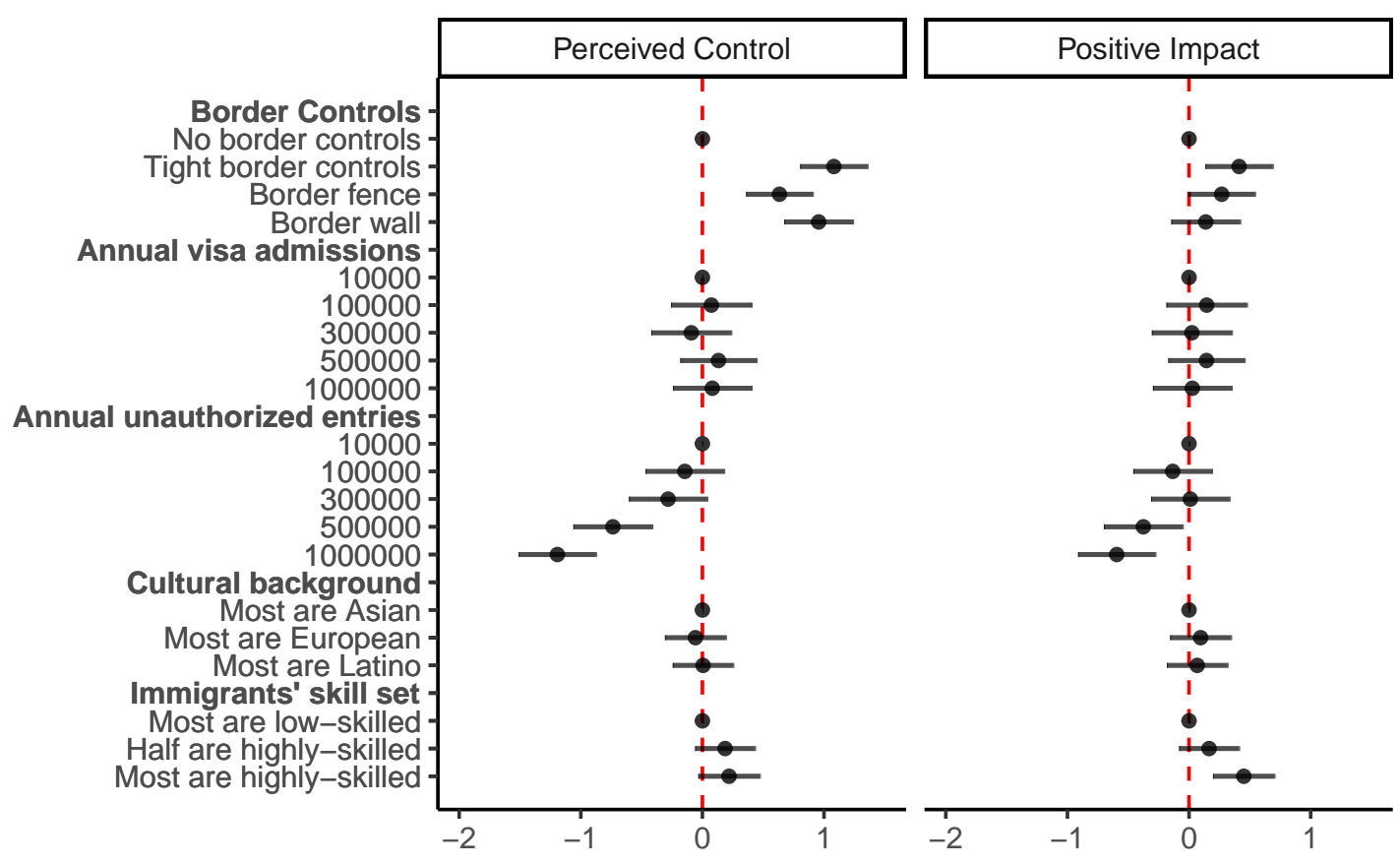

Notes: This figure shows estimates of the effects of the randomly assigned values of immigration attributes on two outcome variables: perceived control over immigration (left panel), and stating that immigration has a positive impact on the nation (right panel). Estimates are based on ordinary least squares models controlling for all treatments including respondent fixed effects (since each respondent evaluates ten immigration scenarios); bars represent $95 \%$ confidence intervals. The points without horizontal bars denote the attribute value that is the reference category for each attribute.

point on the $0-10$ scale, which also equals to a 16 percentage points increase in the probability of positive control evaluations. An annual flow of 500,000 unauthorized immigrants over a flow of 10,000 unauthorized immigrants (the lowest value) reduces perceived control over immigration by 0.7 points. This suggests that border security measures in and of themselves and the number of unauthorized migrants have an independent effect on perceived control 
over immigration.

Both factors also shape views on the impact of immigration on the country as a whole. As shown by the panel on the right, compared to no border controls, tight border controls increase positive evaluations of immigration by 0.41 points on a $0-10$ scale (or 6 percentage points). A large annual influx of one million unauthorized migrants compared to a minor amount of ten thousands decreases positive evaluations by 0.59 points on the same scale. Notably, the level of authorized immigration has no attitudinal effects.

Overall, the results demonstrate that border controls increase public support and perceived control over immigration even when annual immigration levels are held constant. Yet the analysis also indicates that this effect is not driven by border walls. Compared to a border wall, tight border controls either more strongly or similarly increase support for immigration. To foster a public sense of control over immigration, it seems that border barriers, which are more costly and have considerable economic repercussions (Carter and Poast, 2019), are unnecessary. Instead, border patrol agents and officers, surveillance devices and other controls appear as similarly if not more effective. This finding is consistent with the results of the first experiment showing that substantial increases in border security spending have a minor marginal effect on desired levels of immigration compared to smaller increases in spending. 


\section{Conclusion}

A long-standing notion holds that borders are not just lines on a map but rather symbolic boundaries that bound together citizens and foster separation from outsiders and external threats (Hartshorne, 1933; Kristof, 1959). This notion feeds into the intuition that de-bordering-softening borders, de-funding security measures, or tearing down physical interstate barriersshould also mitigate perceived threat from immigration and promote immigrant inclusion.

However, borders turn to symbolic lines of defense against threats in a process of centuries-old framing (Massey, 2016). Such primordial symbolism of the border is sticky and durable, and does not easily disappear when borders are removed or weakened (Pelkmans, 2011; Andrews, 2003). Along with actual external threats that do exist in many cases but are also regularly exaggerated, such symbolism seems to create a situation where people condition their attitudes toward immigration on their sense of control over borders. We tested this hypothesis using three survey experiments. The results of all three experiments support the control hypothesis: increasing border security heightens desired levels of immigration, and decreasing border security reduces support for immigration. Furthermore, the effect of border security measures is not entirely driven by their expected material outcomes in terms of the number or characteristics of immigrants. Rather, perceived control over immigration increases as the border is more closely

policed even when there is no expected change in the size or composition of the immigrant population.

That said, it would be misguided to conclude from our findings that what 
liberal democracies need to enhance political openness to immigration and, more broadly, globalization, among the nations of the world is more border barriers. Rather than portraying borders and the security measures that aim to control them as either intrinsically bad and counterproductive or good and effective, our findings call for looking beyond this false dichotomy and advancing a more nuanced examination of border security measures.

For example, while there is evidence showing that border barriers can substantially reduce terrorist attacks when they are monitored by law enforcement agents (Avdan and Gelpi, 2016; Linebarger and Braithwaite, 2020), there is also evidence suggesting that they could radicalize the target population (Longo, Canetti, and Hite-Rubin, 2014, Gade, 2020). And whereas border walls decrease crime and smuggling in protected towns, they also turn not-protected towns to the new target of smugglers (Getmansky, Grossman, and Wright, 2019). Similarly, borders seem to have a divergent effect on group identities and intergroup relations. On the one hand, the drawing of national borders can define ethnic and national loyalties (Miles and Rochefort, 1991), which could lead to exclusionary attitudes toward outgroups ${ }^{18}$ On the other hand, once such national identities are embedded in people's minds, securing national borders makes people more open to accept outgroup members, as our findings suggest. Still, our analysis also reveals that substantial and more modest changes in border security spending have a similar impact on desired levels of immigration. In other words, relatively small investments in border security could induce a public sense of control of

\footnotetext{
${ }^{18}$ Moreover, border barriers might increase unauthorized migration flows and asylum applications (Massey, Pren, and Durand, 2016 Schon and Leblang, 2021). Such changes in immigration flows might heighten hostility to immigration (Wright, Levy, and Citrin, 2016).
} 
immigration similarly to the one produced by highly costly projects of border fortification and walling.

To examine the scope conditions of the theory, future research could test for the presence of a causal link between border spending and desired levels of immigration in other countries. It was posited that the theory will carry to other countries where immigration is common and where elites link border spending to national security. Australia, for example, is a country where the theory is expected to hold. The causal relationship between border spending and desired levels of immigration should be weaker in countries that do not have highly securitized understandings of national borders or countries where immigration is simply not a salient topic for citizens.

The results also have a number of practical implications for those concerned with strategies for reducing global poverty and global inequality. This is because migration from a low to a high income country can increase the income of migrants by a factor of four or more (Clemens, Montenegro, and Pritchett, 2019), making immigration from poor to rich countries probably the best known anti-poverty intervention (Pritchett, 2018) 19 For similar reasons, the paper has implications for debates around how best to address global inequality and improve the efficiency of the global economy, as migration barriers are the largest remaining source of global economic distortions (Clemens, 2011). Indeed, the distortions created by migration barriers are so large that a majority of the variation in incomes or years of schooling across people is explained simply by the country where you live (Milanovic, 2015).

\footnotetext{
${ }^{19}$ This holds regardless of whether best is defined in terms of payoff to the recipient or in terms of a cost-benefit analysis. One summary of the evidence concluded "there is nothing wrong empirically with the idea of using immigration policy to alleviate poverty" (Oberman, 2015, p. 247).
} 
This has profound implications for global inequality, a topic which deserves more interest in international political economy (Lockwood, 2020).

One response to these startling facts has been for some social movements to try to normalize the idea of allowing large numbers of people to move from low to high-income countries. These movements have sometimes operated under a banner of "open borders." The present paper suggests that this approach may be counterproductive, as the public is more willing to support higher immigration when it is paired with stronger border controls. ${ }^{20}$ Policy entrepreneurs hoping to increase immigration rates should think twice before pushing 'open borders' or similar concepts, as reducing border security seems to lower the desire of the public to accept immigrants.

Notably, in many cases, including the United States, significant controls over borders and immigration already exist, but citizens are unaware of them or misinformed about their effectiveness. For example, and quite strikingly, fewer than half in the United States surveyed in 2018 knew that most immigrants in their country are there legally ${ }^{21}$ Although correcting for misperceptions about the number or characteristics of immigrants does little to affect attitudes toward immigration and does not change policy views (Hopkins, Sides, and Citrin, 2018; Grigorieff, Roth, and Ubfal, 2017), the effect of correcting for misperceptions about existing immigration controls and border security measures has not yet been tested. Our analysis therefore opens up a

\footnotetext{
${ }^{20}$ Hatton $(2017$, p. 474) makes a similar point when he argues that if the $\mathrm{EU}$ is to reform immigration or refugee laws then "border controls need to be tightened and enforced" in order to limit "policy backlash" and the "salience of immigration as a policy issue."

${ }^{21}$ Pew Research, June 28, $2018 . \quad$ Available from: https://www.pewresearch.org/politics/2018/06/28/shifting-public-views-on-legalimmigration-into-the-u-s/.
} 
new avenue for research on potential interventions that can promote public support for immigration.

\section{References}

Abdelgadir, Aala and Vasiliki Fouka (2020). "Political Secularism and Muslim Integration in the West: Assessing the Effects of the French Headscarf Ban". In: American Political Science Review 114.3, pp. 707-723. DOI: 10.1017/s0003055420000106.

Andrews, Molly (2003). "Continuity and discontinuity of East German identity following the fall of the Berlin Wall: A case study". In: Pluto Press.

Avdan, Nazli and Christopher F. Gelpi (2016). "Do Good Fences Make Good Neighbors? Border Barriers and the Transnational Flow of Terrorist Violence". In: International Studies Quarterly, sqw042. DOI: 10.1093/isq/ sqw042.

Bansak, Kirk et al. (2018). "The number of choice tasks and survey satisficing in conjoint experiments". In: Political Analysis 26.1, pp. 112-119.

Bigo, Didier (2002). "Security and Immigration: Toward a Critique of the Governmentality of Unease". In: Alternatives: Global, Local, Political 27.1_suppl, pp. 63-92. DOI: $10.1177 / 03043754020270$ s105.

Brown, Wendy (2010). Walled States, Waning Sovereignty. Zone Books. DoI: $10.2307 /$ j.ctv14gpj55.

Brubaker, Rogers (2009). Citizenship and nationhood in France and Germany. Harvard University Press.

Carter, David B. and Paul Poast (2019). "Barriers to Trade: How Border Walls Affect Trade Relations". In: International Organization 74.1, pp. 165-185. DOI: $10.1017 /$ s0020818319000353.

Clemens, Michael A (2011). "Economics and emigration: Trillion-dollar bills on the sidewalk?" In: Journal of Economic perspectives 25.3, pp. 83-106.

Clemens, Michael A, Claudio E Montenegro, and Lant Pritchett (2019). "The place premium: Bounding the price equivalent of migration barriers". In: Review of Economics and Statistics 101.2, pp. 201-213.

Clifford, Scott, Geoffrey Sheagley, and Spencer Pisont (2021). "Increasing Precision without Altering Treatment Effects: Repeated Measures Designs in Survey Experiments". In: American Political Science Review 115.3, pp. 1048-1065. 
Donnan, Hastings and Thomas M. Wilson (2021). Borders: frontiers of identity, nation and state. Routledge. DOI: 10.4324/9781003084815.

Fouka, Vasiliki (2019). "Backlash: The Unintended Effects of Language Prohibition in U.S. Schools after World War I". In: The Review of Economic Studies 87.1, pp. 204-239. DOI: 10.1093/restud/rdz024.

Gade, Emily Kalah (2020). "Social Isolation and Repertoires of Resistance". In: American Political Science Review 114.2, pp. 309-325. DoI: 10.1017/ s0003055420000015.

Gelfand, Michele J et al. (2011). "Differences between tight and loose cultures: A 33-nation study". In: science 332.6033, pp. 1100-1104.

Getmansky, Anna, Guy Grossman, and Austin L. Wright (2019). "Border Walls and Smuggling Spillovers". In: Quarterly Journal of Political Science 14.3, pp. 329-347. DOI: 10.1561/100.00018094.

Grigorieff, Alexis, Christopher Roth, and Diego Ubfal (2017). "Does information change attitudes towards immigrants? Representative evidence from survey experiments". In: IZA DP No. 10419. URL: ftp://repec .iza. org/RePEc/Discussionpaper/dp10419.pdf.

Hainmueller, Jens, Dominik Hangartner, and Giuseppe Pietrantuono (2015). "Naturalization fosters the long-term political integration of immigrants". In: Proceedings of the National Academy of Sciences 112.41, pp. 1265112656 .

- (2017). "Catalyst or crown: does naturalization promote the long-term social integration of immigrants?" In: American Political Science Review 111.2, pp. 256-276.

Hainmueller, Jens and Daniel J Hopkins (2015). "The hidden American immigration consensus: A conjoint analysis of attitudes toward immigrants". In: American Journal of Political Science 59.3, pp. 529-548.

Hartshorne, Richard (1933). "Geographic and political boundaries in Upper Silesia". In: Annals of the Association of American Geographers 23.4, pp. $195-228$.

Hatton, Timothy J (2017). "Refugees and asylum seekers, the crisis in Europe and the future of policy". In: Economic Policy 32.91, pp. 447-496.

Hopkins, Daniel J, John Sides, and Jack Citrin (2018). "The muted consequences of correct information about immigration". In: Journal of Politics, forthcoming.

Hume, David (2018). David Hume on Morals, Politics, and Society. Ed. by Angela Coventry and Andrew Valls. Yale University Press. ISBN: 9780300240504. 
DOI: doi:10.12987/9780300240504. URL: https://doi.org/10.12987/ 9780300240504 .

Huysmans, Jef (2006). The politics of insecurity: Fear, migration and asylum in the EU. Routledge.

Ibrahim, Maggie (2005). "The Securitization of Migration: A Racial Discourse1". In: International Migration 43.5, pp. 163-187. DOI: 10.1111/ j.1468-2435.2005.00345.x.

Joppke, Christian (2008). "Immigration and the identity of citizenship: the paradox of universalism". In: Citizenship Studies 12.6, pp. 533-546. DOI: $10.1080 / 13621020802450445$.

Kristof, Ladis KD (1959). "The nature of frontiers and boundaries". In: Annals of the Association of American Geographers 49.3, pp. 269-282.

Lahav, Gallya and Marie Courtemanche (2012). "The Ideological Effects of Framing Threat on Immigration and Civil Liberties". In: Political Behavior 34.3, pp. 477-505. DOI: 10.1007/s11109-011-9171-z.

Linebarger, Christopher and Alex Braithwaite (2020). "Do Walls Work? The Effectiveness of Border Barriers in Containing the Cross-Border Spread of Violent Militancy". In: International Studies Quarterly 64.3, pp. 487498. DOI: 10.1093 /isq/sqaa035.

Lockwood, Erin (2020). "The international political economy of global inequality". In: Review of International Political Economy 28.2, pp. 421445. DOI: $10.1080 / 09692290.2020 .1775106$.

Longo, Matthew (2017). The politics of borders: Sovereignty, security, and the citizen after 9/11. Cambridge University Press.

Longo, Matthew, Daphna Canetti, and Nancy Hite-Rubin (2014). "A Checkpoint Effect? Evidence from a Natural Experiment on Travel Restrictions in the West Bank". In: American Journal of Political Science 58.4, pp. 1006-1023. DOI: 10.1111/ajps.12109.

Marbach, Moritz, Jens Hainmueller, and Dominik Hangartner (2018). "The long-term impact of employment bans on the economic integration of refugees". In: Science Advances 4.9, eaap9519.

Massey, Douglas S (2016). "The Mexico-US border in the American imagination". In: Proceedings of the American Philosophical Society 160.2, pp. $160-177$.

Massey, Douglas S, Karen A Pren, and Jorge Durand (2016). "Why border enforcement backfired". In: American journal of sociology 121.5, pp. 15571600 . 
Mendez, Jennifer Bickham and Nancy A Naples (2014). "Border politics: contests over territory, nation, identity, and belonging". In: Border Politics. New York University Press, pp. 1-32.

Migdal, Joel S (2004). Boundaries and belonging: States and societies in the struggle to shape identities and local practices. Cambridge University Press.

Milanovic, Branko (2015). "Global Inequality of Opportunity: How Much of Our Income Is Determined by Where We Live?" In: Review of Economics and Statistics 97.2, pp. 452-460. DOI: 10.1162/rest_a_00432.

Miles, William F. S. and David A. Rochefort (1991). "Nationalism Versus Ethnic Identity in Sub-Saharan Africa". In: American Political Science Review 85.2, pp. 393-403. DOI: 10.2307/1963166.

Mummolo, Jonathan and Erik Peterson (2019). "Demand effects in survey experiments: An empirical assessment". In: American Political Science Review 113.2, pp. 517-529.

Newman, David (2006). "The lines that continue to separate us: borders in ourborderless' world". In: Progress in Human geography 30.2, pp. 143161.

Oberman, Kieran (2015). "Poverty and immigration policy". In: American Political Science Review 109.2, pp. 239-251.

Pelkmans, Mathijs (2011). Defending the Border. Cornell University Press.

Pritchett, Lant (2018). "Alleviating Global Poverty: Labor Mobility, Direct Assistance, and Economic Growth". In: Center for Global Development Working Paper 479.

Sambanis, Nicholas and Moses Shayo (2013). "Social Identification and Ethnic Conflict". In: American Political Science Review 107.2, pp. 294-325. DOI: $10.1017 / \mathrm{s} 0003055413000038$.

Schneider, Anne L and Helen M Ingram (2005). Deserving and entitled: Social constructions and public policy. SUNY Press.

Schon, Justin and David Leblang (2021). "Why Physical Barriers Backfire: How Immigration Enforcement Deters Return and Increases Asylum Applications". In: Comparative Political Studies, p. 001041402110242. DOI: 10.1177/00104140211024282.

Schwartz, Cassilde et al. (2020). "A Populist Paradox? How Brexit Softened Anti-Immigrant Attitudes". In: British Journal of Political Science, 1-21. DOI: $10.1017 /$ S0007123419000656. 
Simmons, Beth A. and Hein E. Goemans (2021). "Built on Borders: Tensions with the Institution Liberalism (Thought It) Left Behind". In: International Organization 75.2, pp. 387-410. DOI: 10.1017/s0020818320000600.

Simmons, Beth A. and Michael R. Kenwick (2021). "Border Orientation in a Globalizing World". In: American Journal of Political Science, forthcoming.

Simmons, Beth A. and Robert Shaffer (2019). "Globalization and Border Securitization in International Discourse". In: SSRN 3480613.

Sniderman, Paul M (2018). "Some advances in the design of survey experiments". In: Annual Review of Political Science 21, pp. 259-275.

Solodoch, Omer (2021). "Regaining Control? The Political Impact of Policy Responses to Refugee Crises". In: International Organization, pp. 1-34. DOI: $10.1017 / \mathrm{S} 0020818321000060$.

Stenner, Karen (2005). The authoritarian dynamic. Cambridge University Press.

Walzer, Michael (2008). Spheres of justice: A defense of pluralism and equality. Basic books.

Wright, Matthew, Morris Levy, and Jack Citrin (2016). "Public attitudes toward immigration policy across the legal/illegal divide: The role of categorical and attribute-based decision-making". In: Political Behavior 38.1, pp. 229-253. 


\author{
Appendix \\ Border Security and Desired \\ Levels of Immigration \\ Ryan C. Briggs and Omer Solodoch
}




\section{Appendix A: Additional results}

These appendices are intended to be published as supplementary information online.

We first present tabular results for both experiments. The specifications for these results were pre-registered. The tabular results reinforce the graphical presentations and qualitative description in the text.

The first two tables present regression results for experiment 1. Following our pre-registered design, we regress the selected immigration level under the treatment condition on the selected immigration level under the control condition and the treatment variable (the change in border spending, denoted as "IV"). Model 1 shows the full (pooled) results and then the second and third models show the effect of only declines and then only increases in border spending. Standard errors are clustered on respondents and all models use weights (described in Appendix B).

The second table is the same as the first, but it also includes a set of control variables. We add dummies marking levels of age, education, and sex. In both tables the pooled effect is significant at $\mathrm{p}<0.001$ and, as noted in the text, the effects of only declines or only increases is not significant. 
Table A-1: Analysis 1: No controls

\begin{tabular}{lccc}
\hline & Full & Declines & Increases \\
\hline (Intercept) & $146681.80^{* * *}$ & $130879.70^{* * *}$ & $195609.85^{* * *}$ \\
& $(18890.89)$ & $(31478.79)$ & $(36807.48)$ \\
IV & $2232.76^{* * *}$ & 1602.61 & -749.83 \\
& $(575.36)$ & $(1540.58)$ & $(1947.02)$ \\
DV_control & $0.81^{* * *}$ & $0.81^{* * *}$ & $0.81^{* * *}$ \\
& $(0.02)$ & $(0.03)$ & $(0.03)$ \\
\hline $\mathrm{R}^{2}$ & 0.60 & 0.61 & 0.58 \\
Adj. R ${ }^{2}$ & 0.60 & 0.61 & 0.58 \\
Num. obs. & 1720 & 861 & 859 \\
RMSE & 322685.28 & 313957.14 & 330925.32 \\
\hline
\end{tabular}


Table A-2: Analysis 1: With controls

\begin{tabular}{|c|c|c|c|}
\hline & Full & Declines & Increases \\
\hline (Intercept) & $\begin{array}{c}224629.06^{* * *} \\
(53932.63)\end{array}$ & $\begin{array}{c}318638.57^{* *} \\
(96342.92)\end{array}$ & $\begin{array}{c}177588.20 \\
(102532.85)\end{array}$ \\
\hline IV & $\begin{array}{c}2258.24^{* * *} \\
(575.46)\end{array}$ & $\begin{array}{c}1987.45 \\
(1494.04)\end{array}$ & $\begin{array}{c}-822.80 \\
(1964.51)\end{array}$ \\
\hline DV_control & $\begin{array}{c}0.81^{* * *} \\
(0.03)\end{array}$ & $\begin{array}{c}0.82^{* * *} \\
(0.03)\end{array}$ & $\begin{array}{c}0.80^{* * *} \\
(0.03)\end{array}$ \\
\hline Age25-34 & $\begin{array}{c}-113433.04^{* *} \\
(41071.11)\end{array}$ & $\begin{array}{c}-177806.44^{* *} \\
(61593.50)\end{array}$ & $\begin{array}{l}-46081.40 \\
(67825.27)\end{array}$ \\
\hline Age35 - 44 & $\begin{array}{c}-105096.93^{* *} \\
(36830.89)\end{array}$ & $\begin{array}{c}-171607.26^{* *} \\
(58620.54)\end{array}$ & $\begin{array}{l}-39027.12 \\
(60031.01)\end{array}$ \\
\hline Age $45-54$ & $\begin{array}{c}-113521.12^{* *} \\
(37138.31)\end{array}$ & $\begin{array}{c}-178718.80^{* *} \\
(59462.04)\end{array}$ & $\begin{array}{l}-48147.91 \\
(59478.88)\end{array}$ \\
\hline Age $55-59$ & $\begin{array}{c}-97250.56^{*} \\
(44135.32)\end{array}$ & $\begin{array}{c}-135410.82^{*} \\
(65277.86)\end{array}$ & $\begin{array}{l}-62919.37 \\
(66765.74)\end{array}$ \\
\hline Age60 - 64 & $\begin{array}{l}-98540.54 \\
(53547.38)\end{array}$ & $\begin{array}{c}-105463.05 \\
(73954.53)\end{array}$ & $\begin{array}{l}-91563.61 \\
(73791.49)\end{array}$ \\
\hline Age65 or older & $\begin{array}{c}-131307.90^{* * *} \\
(35556.93)\end{array}$ & $\begin{array}{c}-185334.56^{* *} \\
(55696.04)\end{array}$ & $\begin{array}{l}-80150.23 \\
(55628.01)\end{array}$ \\
\hline AgePrefer not to answer & $\begin{array}{c}343740.63^{* * *} \\
(30930.05)\end{array}$ & $\begin{array}{l}-32100.62 \\
(48956.61)\end{array}$ & $\begin{array}{c}759854.70^{* * *} \\
(55571.69)\end{array}$ \\
\hline EducationHigh school or equivalent & $\begin{array}{c}52356.44 \\
(45330.24)\end{array}$ & $\begin{array}{c}3168.57 \\
(68655.51)\end{array}$ & $\begin{array}{c}92711.57 \\
(71778.65)\end{array}$ \\
\hline EducationSome college, less than 4-yr degree & $\begin{array}{c}21989.49 \\
(42792.44)\end{array}$ & $\begin{array}{l}-68687.68 \\
(66455.57)\end{array}$ & $\begin{array}{l}104190.46 \\
(69426.12)\end{array}$ \\
\hline EducationBachelor's degree or higher & $\begin{array}{c}41014.31 \\
(43577.91)\end{array}$ & $\begin{array}{l}-23633.96 \\
(64524.11)\end{array}$ & $\begin{array}{c}99728.23 \\
(69853.29)\end{array}$ \\
\hline EducationPrefer not to answer & $\begin{array}{l}-24962.59 \\
(46129.22)\end{array}$ & $\begin{array}{l}149569.21^{*} \\
(68910.67)\end{array}$ & $\begin{array}{c}-225184.41^{* *} \\
(76831.92)\end{array}$ \\
\hline SexFemale & $\begin{array}{l}-17295.18 \\
(22540.23)\end{array}$ & $\begin{array}{l}-15728.47 \\
(28781.60)\end{array}$ & $\begin{array}{l}-20316.09 \\
(29156.86)\end{array}$ \\
\hline $\mathrm{R}^{2}$ & 0.60 & 0.63 & 0.59 \\
\hline Adj. $R^{2}$ & 0.60 & 0.62 & 0.59 \\
\hline Num. obs. & 1720 & 861 & 859 \\
\hline RMSE & 320710.44 & 309548.12 & 329143.48 \\
\hline
\end{tabular}


We next in Figure A-1 present a version of Figure 2a that is zoomed out to show all of the data. Figure 2a, which is in the main text, is simply a crop of this figure. Aside from the crop, the figure in the main text also shows the mean of the $\mathrm{y}$-values per unique $\mathrm{x}$-axis value in order to aid visual interpretation. Figure A-1 was pre-registered.

Figure A-1: Experiment 1, all data.

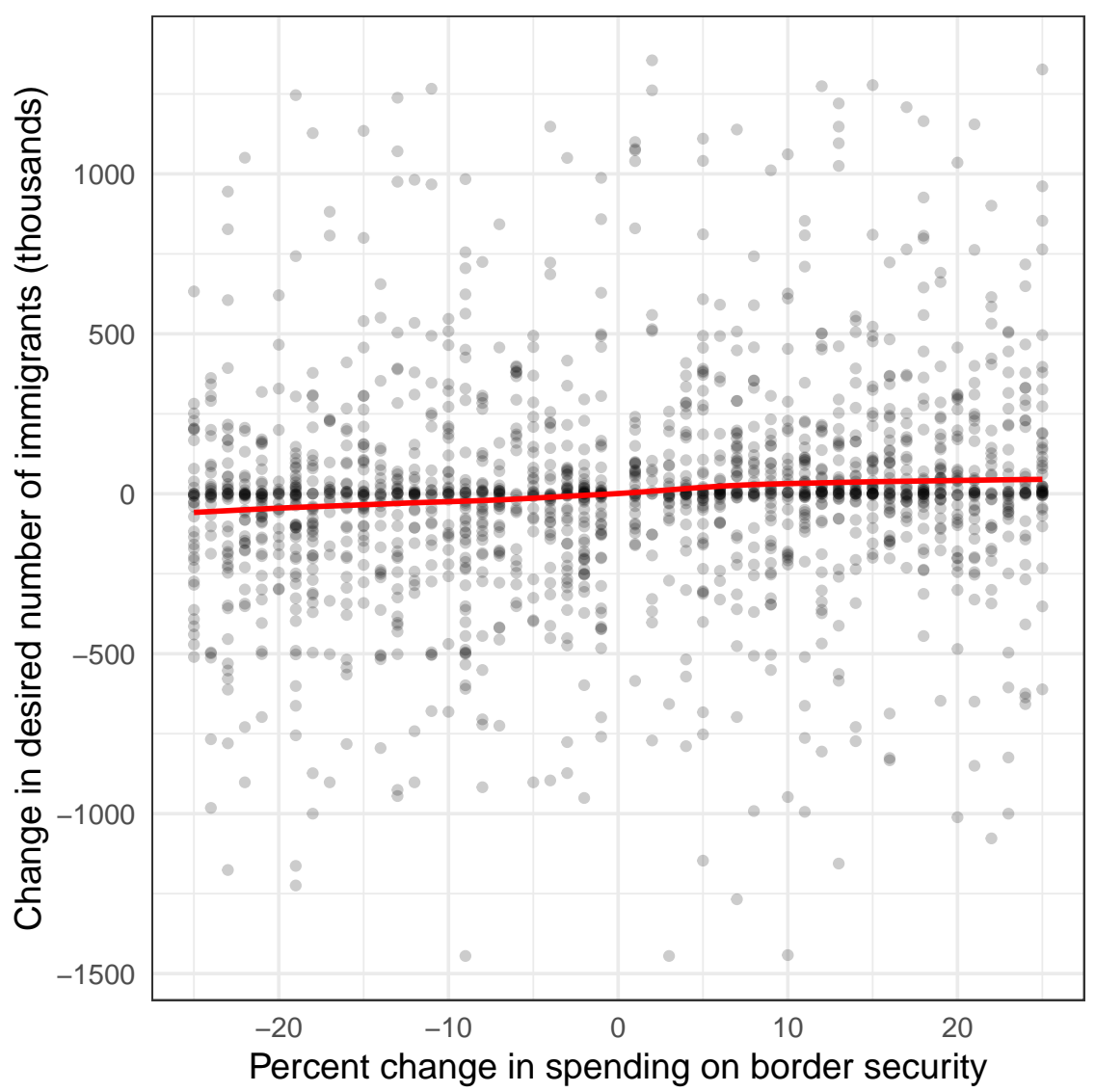


The next two tables present results from experiment 2. We regress a dummy variable marking if a profile was selected on border spending, the immigration rate, and their interaction. Unlike in figure 4 , we treat these variables as continuous. Standard errors are clustered on respondents and all models use weights (described in Appendix B). The second table in this section is the same as the first, but it also includes a set of control variables. We add dummies marking levels of age, education, and sex.

The key result is that in the pooled analysis (and regardless of the control variables), the interaction between border spending and the immigration rate is significant at $\mathrm{p}<0.05$. The coefficient for the interaction is small $(0.0014$ in both cases), and the best way to really see the results is just to look at Figure 4 .

Table A-5 presents results from Figure 4 in tabular form (columns 1 and 2). Column 3 formally tests the interaction effects and shows that the differences between the effects of immigration in columns 1 (conditional on less or no change in border security spending) and 2 (conditional on more spending) are statistically significant. 
Table A-3: Analysis 2: No controls

\begin{tabular}{lcccc}
\hline & Pooled & Allow more Im. & Prefer current & Allow fewer Im. \\
\hline Intercept & $.5687^{* * *}$ & $.4153^{* * *}$ & $.4881^{* * *}$ & $.6806^{* * *}$ \\
& $(.0239)$ & $(.0432)$ & $(.0644)$ & $(.0305)$ \\
Border Spending & .0036 & -.0087 & .0091 & .0083 \\
& $(.0042)$ & $(.0078)$ & $(.0117)$ & $(.0054)$ \\
Immigration Rate & $-.0242^{* * *}$ & $.0210^{* * *}$ & -.0167 & $-.0522^{* * *}$ \\
& $(.0044)$ & $(.0077)$ & $(.0109)$ & $. .0057)$ \\
Border * Immigration & $.0014^{* *}$ & .0009 & .0020 & .0016 \\
& $(.0007)$ & $(.0013)$ & $. .0018)$ & $. .0010)$ \\
\hline $\mathrm{R}^{2}$ & .0113 & .0178 & .0123 & .0601 \\
Adj. R ${ }^{2}$ & .0111 & .0171 & .0110 & .0597 \\
Num. obs. & 14210 & 4382 & 2310 & 7518 \\
RMSE & .4972 & .4951 & .4828 & .4895 \\
\hline
\end{tabular}

${ }^{* * *} p<0.01,{ }^{* *} p<0.05,{ }^{*} p<0.1$. All models include post-stratification weights and cluster standard errors on respondents.

Table A-4: Analysis 2: With controls

\begin{tabular}{lcccc}
\hline & Pooled & Allow more Im. & Prefer current & Allow fewer Im. \\
\hline Intercept & $.5651^{* * *}$ & $.4128^{* * *}$ & $.4942^{* * *}$ & $.6681^{* * *}$ \\
& $(.0244)$ & $(.0453)$ & $(.0716)$ & $(.0314)$ \\
Border Spending & .0036 & -.0087 & .0089 & .0083 \\
& $(.0042)$ & $(.0078)$ & $(.0118)$ & $(.0054)$ \\
Immigration Rate & $-.0243^{* * *}$ & $.0210^{* * *}$ & -.0169 & $-.0524^{* * *}$ \\
& $(.0044)$ & $(.0077)$ & $(.0111)$ & $(.0057)$ \\
Border * Immigration & $.0014^{* *}$ & .0009 & .0020 & .0016 \\
& $(.0007)$ & $(.0013)$ & $(.0018)$ & $(.0010)$ \\
\hline $\mathrm{R}^{2}$ & .0113 & .0179 & .0123 & .0602 \\
Adj. $\mathrm{R}^{2}$ & .0102 & .0147 & .0067 & .0583 \\
Num. obs. & 14210 & 4382 & 2310 & 7518 \\
RMSE & .4975 & .4957 & .4839 & .4899 \\
\hline
\end{tabular}

${ }^{* * *} p<0.01,{ }^{* *} p<0.05,{ }^{*} p<0.1$. All models include post-stratification weights and cluster standard errors on respondents. Includes controls for age, gender, and education. 
Table A-5: Experiment 2, Interaction Effects

\begin{tabular}{|c|c|c|c|}
\hline & \multicolumn{3}{|c|}{ Border security spending } \\
\hline & Less/no change: & More & Full sample \\
\hline Immigration: $-15 \%$ & $\begin{array}{c}-0.07^{* *} \\
(0.03)\end{array}$ & $\begin{array}{c}0.05 \\
(0.03)\end{array}$ & $\begin{array}{c}-0.06^{*} \\
(0.03)\end{array}$ \\
\hline$-10 \%$ & $\begin{array}{l}-0.05 \\
(0.03)\end{array}$ & $\begin{array}{c}0.01 \\
(0.03)\end{array}$ & $\begin{array}{l}-0.03 \\
(0.03)\end{array}$ \\
\hline$-5 \%$ & $\begin{array}{c}-0.08^{* *} \\
(0.03)\end{array}$ & $\begin{array}{c}0.04 \\
(0.03)\end{array}$ & $\begin{array}{c}-0.08^{* *} \\
(0.03)\end{array}$ \\
\hline No change & $\begin{array}{c}-0.10^{* * *} \\
(0.03)\end{array}$ & $\begin{array}{c}0.03 \\
(0.03)\end{array}$ & $\begin{array}{c}-0.10^{* * *} \\
(0.03)\end{array}$ \\
\hline$+5 \%$ & $\begin{array}{l}-0.10^{* * *} \\
(0.03)\end{array}$ & $\begin{array}{c}0.01 \\
(0.03)\end{array}$ & $\begin{array}{c}-0.08^{* *} \\
(0.03)\end{array}$ \\
\hline$+10 \%$ & $\begin{array}{c}-0.16^{* * *} \\
(0.03)\end{array}$ & $\begin{array}{c}0.01 \\
(0.03)\end{array}$ & $\begin{array}{c}-0.15^{* * *} \\
(0.03)\end{array}$ \\
\hline$+15 \%$ & $\begin{array}{l}-0.21^{* * *} \\
(0.03)\end{array}$ & $\begin{array}{c}-0.08^{* *} \\
(0.03)\end{array}$ & $\begin{array}{c}-0.20^{* * *} \\
(0.03)\end{array}$ \\
\hline$+20 \%$ & $\begin{array}{c}-0.21^{* * *} \\
(0.03)\end{array}$ & $\begin{array}{c}-0.08^{* *} \\
(0.03)\end{array}$ & $\begin{array}{c}-0.19^{* * *} \\
(0.03)\end{array}$ \\
\hline Border security & & & $\begin{array}{l}-0.07^{*} \\
(0.03)\end{array}$ \\
\hline$-15 \%$ x Border security & & & $\begin{array}{c}0.14^{* * *} \\
(0.04)\end{array}$ \\
\hline$-10 \%$ x Border securitye & & & $\begin{array}{c}0.06 \\
(0.04)\end{array}$ \\
\hline$-5 \%$ x Border security & & & $\begin{array}{c}0.13^{* * *} \\
(0.04)\end{array}$ \\
\hline No change $\mathrm{x}$ Border security & & & $\begin{array}{c}0.16^{* * *} \\
(0.04)\end{array}$ \\
\hline$+5 \%$ x Border security & & & $\begin{array}{l}0.10^{* *} \\
(0.04)\end{array}$ \\
\hline$+10 \%$ x Border security & & & $\begin{array}{c}0.18^{* * *} \\
(0.04)\end{array}$ \\
\hline$+15 \%$ x Border security & & & $\begin{array}{c}0.13^{* * *} \\
(0.04)\end{array}$ \\
\hline$+20 \%$ x Border security & & & $\begin{array}{l}0.12^{* *} \\
(0.04)\end{array}$ \\
\hline Respondent FE & $\checkmark$ & $\checkmark$ & $\checkmark$ \\
\hline $\mathrm{R}^{2}$ & 0.11 & 0.15 & 0.01 \\
\hline Adj. $R^{2}$ & -0.02 & -0.01 & -0.06 \\
\hline Num. obs. & 7967 & 6243 & 14210 \\
\hline
\end{tabular}

Notes: The dependent variable is a binary indicator that equals 1 if respondents preferred the policy modification. Border security is a dummy for increases in border security spending. Percentage changes represent changes from the present rate of immigration. ${ }^{* * *} p<0.001 ;{ }^{* *} p<0.01 ;{ }^{*} p<0.05$.

A-8 
Table A-6: Experiment 2, Interaction Effects by Pre-Treatment Immigration Preferences

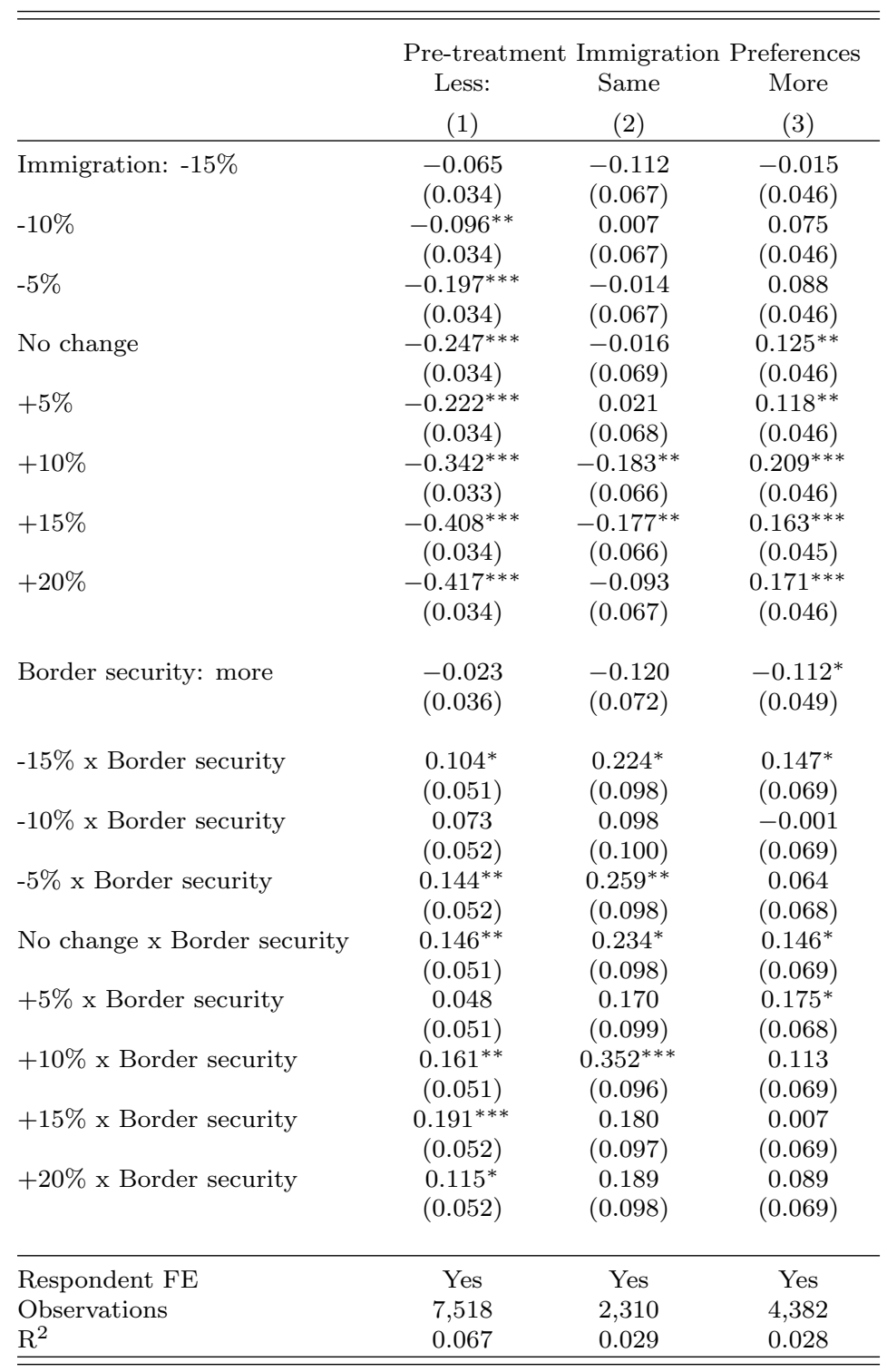

Notes: Each model divides respondents by their response to the control DV question from the first analysis, as indicated by the columns' headers. The dependent variable is a binary indicator that equals 1 if respondents preferred the policy modification. Border security is a dummy for increases in border security spending. Percentage changes represent changes from the present rate of immigration. ${ }^{* * *} p<0.001$; ${ }^{* *} p<0.01 ;{ }^{*} p<0.05$. 
Next, figure A-2 presents the full version of the exact same analysis presented in figure 5. The four attributes, or sets of treatments, which were not shown in figure 5 and are presented here, are: deportation policy, language requirements, birthright citizenship, and welfare entitlement. Manipulating these variables in the experiment allows us to exclude the possibility that the effect of border controls is driven by general policy restrictiveness and raises confidence in attributing the effect to the specific border security measure.

In addition, the order of all nine attributes was randomly assigned. Thus, the conjoint design and, more specifically, the number of attributes and their random order, should considerably reduce demand effects and make it very difficult for respondents to figure out what the focus of this research is. 
Figure A-2: Border controls, immigration flows, and attitudes toward immigration

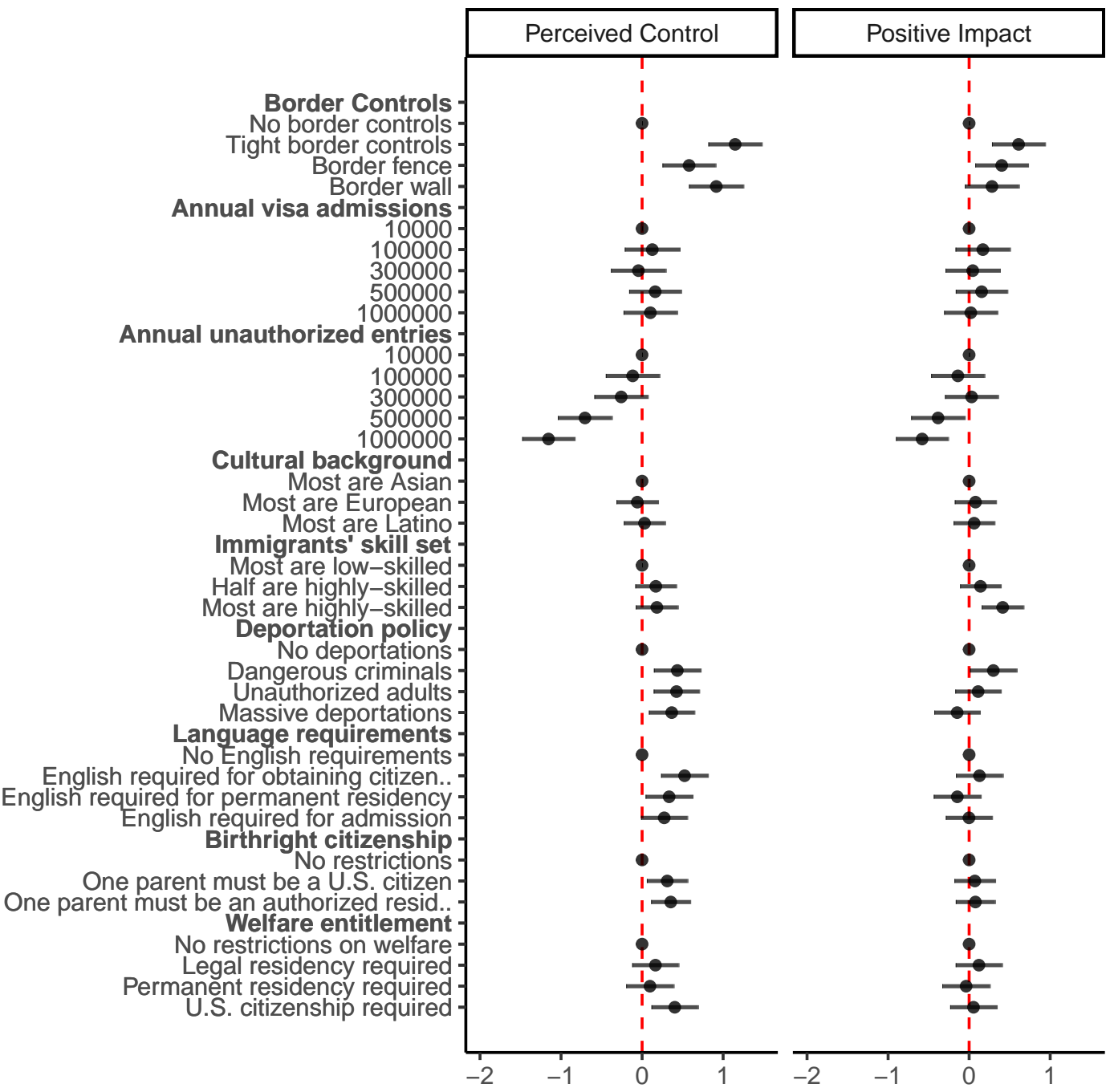

Notes: This figure presents the full version of the exact same analysis presented in figure 5 The four attributes, or sets of treatments, which were not shown in figure 5 and are presented here, are: deportation policy, language requirements, birthright citizenship, and welfare entitlement. 


\section{Appendix B: Balance}

This section describes how the sample matches the population on some key demographic characteristics. Qualtrics used quota sampling to generate a sample that was roughly matched on sex, age bands, and US region. We then used survey weights (calculated with raking, as per our pre-registration plan) to correct for residual imbalance on sex and age and to weight on US state (rather than region) and level of education. All population figures come from 2018 CPS data.

Table A-7 shows imbalance on sex and table $\mathrm{A}-8$ shows imbalance on age. Qualtrics used quota sampling to create balance on these variables and the unweighted sample shows only a small degree of imbalance. This imbalance is fully rectified with the survey weights.

Table A-7: Sex Balance

\begin{tabular}{lccccc}
\hline Sex & Population & Sample & Sample-Pop & Weighted & Weight-Pop \\
\hline Female & 0.52 & 0.51 & -0.01 & 0.52 & 0 \\
Male & 0.48 & 0.49 & 0.01 & 0.48 & 0 \\
\hline
\end{tabular}


Table A-8: Age Balance

\begin{tabular}{lccccc}
\hline Age & Population & Sample & Sample-Pop & Weighted & Weight-Pop \\
\hline $18-24$ & 0.12 & 0.13 & 0.01 & 0.12 & 0 \\
$25-34$ & 0.18 & 0.18 & 0 & 0.18 & 0 \\
$35-44$ & 0.16 & 0.17 & 0.01 & 0.16 & 0 \\
$45-54$ & 0.17 & 0.18 & 0.01 & 0.17 & 0 \\
$55-59$ & 0.09 & 0.09 & 0.01 & 0.09 & 0 \\
$60-64$ & 0.08 & 0.07 & -0.01 & 0.08 & 0 \\
65 or older & 0.21 & 0.18 & -0.03 & 0.21 & 0 \\
\hline
\end{tabular}


Table A-9 shows imbalance on level of education. Qualtrics did not use quota sampling to balance level of education, and the sample over-represents people with some college and under-represents high school dropouts. This imbalance is largely (but not fully) rectified by the survey weights.

Table A-9: Education Balance

\begin{tabular}{llllll}
\hline Education & Population & Sample & Sample-Pop & Weighted & Weight-Pop \\
\hline No HS diploma & 0.15 & 0.04 & -0.11 & 0.11 & -0.04 \\
High school or equiv. & 0.27 & 0.27 & 0 & 0.29 & 0.01 \\
Some col., < 4-yr degree & 0.27 & 0.38 & 0.11 & 0.29 & 0.02 \\
BA or higher & 0.31 & 0.31 & 0 & 0.32 & 0.01 \\
\hline
\end{tabular}


Figure A-3 shows imbalance across states in the continental US with and without the survey weights ${ }^{22}$ Imbalance is never particularly large, but is smaller with the weights.

Figure A-3: Balance across states.

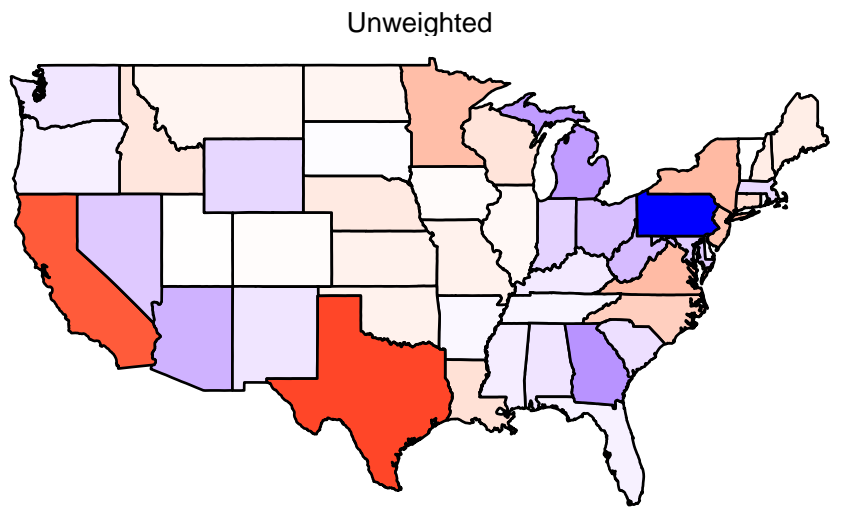

Deviation from population

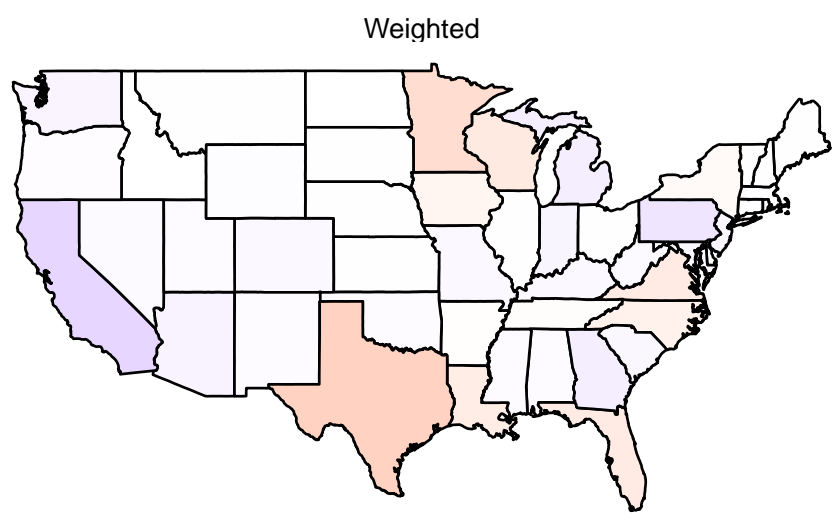

0.02

0.01

0.00

$-0.01$

$-0.02$

\footnotetext{
${ }^{22}$ Imbalance in Hawaii and Alaska also shrink with the weights, and are not shown because of their small population shares and to make a map that is easier to read.
} 


\section{Appendix C: Deviations from pre-registration plan}

Before running the first survey, a pre-analysis plan was registered with EGAP ([REDACTED $]$ ). We pre-registered a qualitative summary of the plan as well as sample code. We describe below the deviations from the plan. We made no substantive deviations from the plan or code in the sampling, data cleaning, or analysis of experiment 1 . We made more changes to experiment 2 , which we discuss below.

Experiment 3 was not pre-registered, but was conducted and analyzed independently for another purpose by one co-author before this article was conceived. This Appendix only discusses the pre-registration of experiments 1 and 2.

\subsection{Sampling}

We aimed to collect 1,000 responses but Qualtrics gave us 1,015 responses. We used the full sample that Qualtrics gave us $(N=1,015)$.

\subsection{Data cleaning}

1. Our agreement with Qualtrics included a time screener (dropping respondents who completed in less than $30 \%$ of the median response time). Our pre-registered code included the code to isolate these re- 
spondents. However, Qualtrics dropped these respondents on their end (so they never entered our dataset). Accordingly, we had to change our code so that we did not drop additional respondents. This change alters the dataset, but is consistent with the motivation of the original code and pre-registration document.

2. When dropping outliers, we planned to drop observations with control DV values larger than or equal to the 99th percentile or smaller than or equal to the first percentile. However, upon seeing the data we realized that the 1st percentile was 0 and the 99th was 2 million - and no observations were trimmed because we had ignored the "or equal to" part. Hence, we modified the code to drop observations that were also equal to the 99 th or 1st percentile. Again, this change is fully in line with our pre-registered qualitative statement.

\subsection{Analysis 1}

1. The scatter plot code that we originally pre-registered drew a loess line without weighting the observations. The regressions use survey weights, and now the plot does too. Adding the weights moderately weakens the effect of border spending changes.

2. In the main text we show a crop of the originally pre-registered figure. The loess fit line is exactly the same, but the cropped figure allows one to more clearly see the results. The figure as originally pre-registered 
is in Appendix A, Figure A-1.

\subsection{Analysis 2}

We pre-registered two analyses for experiment 2. The first was a simple OLS regression of the binary dependent variable on each of the two independent variables and their interaction, where each independent variable runs from 1 to 9 and is treated as continuous. We did this with and without controls. We report this result as pre-registered in the main text and present the tables in Appendix A.

The second analysis was a regression of the binary dependent variable on the continuous change in the immigration rate, a set of dummies representing every level of the change in border security variable, and the interaction between the continuous change in immigration rate and the set of dummies. Intuitively, this fits the linear effect of the change in the immigration rate on the probability of selection for each discrete level of border security spending. We then planned on making a heat map of the resulting probabilities because it is very hard to interpret a table with so many interaction terms.

Unfortunately, the graphical analysis also produces results that are very hard to interpret when run on the real data (it 'worked' in our simulated data because the underlying patterns were more obvious). For transparency, we report the pre-registered graphical result in Figure A-4. The results does show the anticipated effect in the full sample, but it's very hard to read because the direction of the effect never flips (and so the colors never flip). 
Figure A-4: Probability of selecting a given modification to immigration policy

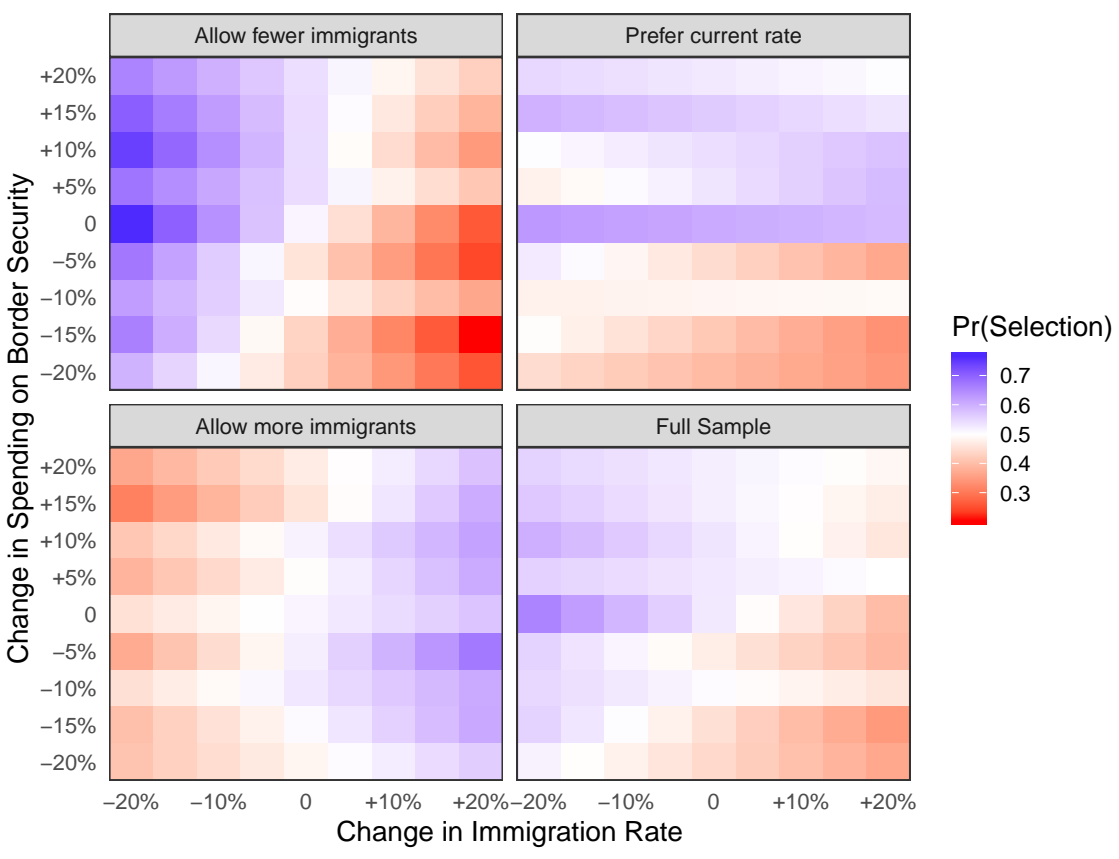


What we wanted to show was how the effect of immigration on the probability of profile selection is larger or smaller at different levels of border spending, but all that one can really get from Figure A-4 is the point probabilities. It is nearly impossible to read the changes in color horizontally and then compare this across the rows.

Instead of putting Figure A-4 in the main text, we greatly simplified the analysis and graphical presentation by grouping the data into positive or negative changes in border security, and then examined how changes in immigration rates correlated with the probability of profile selection for those who saw increases or decreases in border security. The result is Figure 4 , which is probing the same interaction as the pre-registered analysis but it is easier to understand and read.

In sum, after seeing the data we realized the second part of our second analysis was hard to interpret so we simplified the analysis and presentation. The first part of the second analysis, as well as all of the prior portions of the analysis, remain as pre-registered. 